\title{
Evidence That Sleep Deprivation Downregulates Dopamine D2R in Ventral Striatum in the Human Brain
}

\author{
Nora D. Volkow, ${ }^{1,2}$ Dardo Tomasi, ${ }^{3}$ Gene-Jack Wang, ${ }^{3}$ Frank Telang, ${ }^{2}$ Joanna S. Fowler, ${ }^{3}$ Jean Logan, ${ }^{3}$ \\ Helene Benveniste, ${ }^{4}$ Ron Kim, ${ }^{2}$ Panayotis K. Thanos, ${ }^{2}$ and Sergi Ferré ${ }^{1}$ \\ ${ }^{1}$ National Institute on Drug Abuse, Bethesda, Maryland 20892, ${ }^{2}$ National Institute on Alcohol Abuse and Alcoholism, Bethesda, Maryland 20892, ${ }^{3}$ Medical \\ Department Brookhaven National Laboratory, Upton, New York 11973, and ${ }^{4}$ Department of Anesthesiology, Stony Brook University, Stony Brook, New \\ York 11794
}

Dopamine D2 receptors are involved with wakefulness, but their role in the decreased alertness associated with sleep deprivation is unclear. We had shown that sleep deprivation reduced dopamine D2/D3 receptor availability (measured with PET and [ $\left.{ }^{11} \mathrm{C}\right]$ raclopride in controls) in striatum, but could not determine whether this reflected dopamine increases $\left(\left[{ }^{11} \mathrm{C}\right]\right.$ raclopride competes with dopamine for D2/D3 receptor binding) or receptor downregulation. To clarify this, we compared the dopamine increases induced by methylphenidate (a drug that increases dopamine by blocking dopamine transporters) during sleep deprivation versus rested sleep, with the assumption that methylphenidate's effects would be greater if, indeed, dopamine release was increased during sleep deprivation. We scanned 20 controls with $\left[{ }^{11} \mathrm{C}\right]$ raclopride after rested sleep and after 1 night of sleep deprivation; both after placebo and after methylphenidate. We corroborated a decrease in D2/D3 receptor availability in the ventral striatum with sleep deprivation (compared with rested sleep) that was associated with reduced alertness and increased sleepiness. However, the dopamine increases induced by methylphenidate (measured as decreases in D2/D3 receptor availability compared with placebo) did not differ between rested sleep and sleep deprivation, and were associated with the increased alertness and reduced sleepiness when methylphenidate was administered after sleep deprivation. Similar findings were obtained by microdialysis in rodents subjected to 1 night of paradoxical sleep deprivation. These findings are consistent with a downregulation of D2/D3 receptors in ventral striatum with sleep deprivation that may contribute to the associated decreased wakefulness and also corroborate an enhancement of D2 receptor signaling in the arousing effects of methylphenidate in humans.

\section{Introduction}

There is increasing evidence that dopamine (DA) modulates wakefulness exerting a wake promoting action. Indeed, drugs that enhance DA signaling through DA transporter (DAT) blockade [methylphenidate (MP), modafinil] or by releasing DA (amphetamine) increase wakefulness in human subjects (Killgore et al., 2008), promote wakefulness in normal and narcoleptic animals (Nishino et al., 1998), and actively induce emergence from anesthesia (Solt et al., 2011). Similarly, mice with a deletion of the DAT gene, which results in enhanced DA neurotransmission, display increased wakefulness (Wisor et al., 2001), whereas patients with Parkinson's disease, who suffer from DA depletion, experience excessive daytime sleepiness (Arnulf et al., 2002). The

\footnotetext{
Received Jan. 4, 2012; revised March 18, 2012; accepted March 23, 2012

Author contributions: N.D.V., J.S.F., J.L., and H.B. designed research; D.T., G.-J.W., F.T., J.S.F., J.L., H.B., R.K., P.K.T., and S.F. performed research; N.D.V., G.-J.W., F.T., J.S.F., H.B., P.K.T., and S.F. analyzed data; N.D.V. wrote the paper.

Research was supported by the National Institutes of Health Intramural Research Program (National Institute on Alcohol Abuse and Alcoholism) and by the Department of Energy (Grant DE-AC01-76CH00016). We thank David Schlyer, David Alexoff, Paul Vaska, Colleen Shea, Youwen Xu, Pauline Carter, Christopher Wong, Millard Jayne, and Karen Apelskog for their contributions; and Ruben Baler for editorial assistance.

Correspondence should be addressed to Dr. Nora D. Volkow, National Institute on Drug Abuse, 6001 Executive Boulevard, Room 5274, Bethesda, MD 20892. E-mail: nvolkow@nida.nih.gov.

DOI:10.1523/JNEUROSCI.0045-12.2012

Copyright $\odot 2012$ the authors $\quad 0270-6474 / 12 / 326711-07 \$ 15.00 / 0$
}

wake-promoting effects of DA appear to be mediated in part through DA D2 receptors (D2Rs) (Qu et al., 2010). In fact, antipsychotic drugs that block D2Rs are sedating in humans (Baldessarini, 1990) and decrease wakefulness in laboratory animals (Ongini et al., 1993). Similarly, D2R knock-out (KO) mice show decreased wakefulness and an attenuated response to the wakepromoting effects of the DAT blocker GBR12909 (Qu et al., 2010). Moreover, recent studies in flies document an involvement of D2R in DA-induced arousal during the dark but not the light period (Shang et al., 2011).

Using positron emission tomography (PET), we previously showed that sleep deprivation (SD) in healthy controls decreased the specific binding of $\left[{ }^{11} \mathrm{C}\right]$ raclopride (a radiotracer that binds to D2 and D3 receptors when these are not bound to DA) in striatum (Volkow et al., 2008). Thus, we interpreted our findings to reflect increased DA release during SD. However, we could not rule out the possibility that the results reflected downregulation of D2/D3R and/or reduced receptor affinity. Here we test this possibility by comparing the dopamine increases induced by MP when given during the rested waking (RW) state versus when its given during SD in healthy volunteers. Since MP blocks DAT (Volkow et al., 1998), we reasoned that if there was increased DA release during $\mathrm{SD}$, then $\mathrm{MP}$-induced $\mathrm{DA}$ increases would be greater during SD than during RW; whereas, if there was no difference, this would suggest a downregulation of D2/D3R. We 
previously validated the use of $\left[{ }^{11} \mathrm{C}\right]$ raclopride to measure DA increases induced by MP in the human brain (Volkow et al., 1994, 2001; Wang et al., 1999) and the use of MP (by blocking DA reuptake) as a strategy to enhance DA signals resulting from DA release (Volkow et al., 2002b).

For this purpose, we tested 20 healthy controls with PET and $\left[{ }^{11} \mathrm{C}\right]$ raclopride during RW and during SD both with placebo and with MP (40 mg, p.o.). Our initial hypothesis was that decreases in D2/D3R availability seen after SD reflect increases in DA release, and thus MP-induced increases in DA would be enhanced during SD compared with RW. In parallel, we conducted microdialysis studies in rodents to compare the extracellular concentration of DA in nucleus accumbens (NAc; located in ventral striatum) of sleep-deprived animals with those of control rats before and after MP (1 mg/kg, i.v.).

\section{Materials and Methods}

Subjects. Twenty healthy, nonsmoking, right-handed males $(32.5 \pm 9$ years of age; $14 \pm 2$ years of education; body mass index, $26 \pm 3$; 9 African Americans, 8 Caucasians, 3 other) participated in the study. Participants were screened carefully with a detailed medical history, physical and neurological examinations, EKG, breath $\mathrm{CO}$, routine blood tests and urinalysis, and urine toxicology for psychotropic drugs to ensure they fulfilled inclusion and exclusion criteria. Inclusion criteria were as follows: (1) ability to understand and give informed consent; and (2) 18-50 years of age. Exclusion criteria were as follows: (1) urine positive for psychotropic drugs; (2) present use of or history of dependence on alcohol or other drugs of abuse (including current dependence on nicotine); (3) present use of or history of neurological or psychiatric disorders; (4) use of psychoactive medications in the past month (i.e., opiate analgesics, stimulants, sedatives); (5) use of prescription (nonpsychiatric) medications (i.e., antihistamines); (6) medical conditions that may alter cerebral function; (7) cardiovascular and metabolic diseases; (8) history of head trauma with loss of consciousness of $>30 \mathrm{~min}$; (9) history of sleep disorders (if they responded affirmatively to having problems falling asleep, staying asleep, feeling tired upon wakening, and/or required medications to help them sleep and/or if they had a history of or present experience of sleep apnea or restless leg syndrome); and (10) work that required shift hours. Subjects were asked to keep a diary of the number of hours slept per night for the 2 week duration of the study (from evaluation to completion of the PET scans), and this corresponded to an average of $7 \pm 1 \mathrm{~h}$ per night (range 5-9 h per night). Signed informed consents were obtained from the subjects before participation, as approved by the Committee on Research Involving Human Subjects, Stony Brook University, and the Radioactive Drug Research Committee, Brookhaven National Laboratory.

Behavioral measures. Subjects were asked to rate self-reports for descriptors of "alert," "sleepiness," and "tired," on a scale of 1-10 with 1 being not at all and 10 being very intense. Self-reports were obtained at 30, 60 (just before radiotracer injection), and $90 \mathrm{~min}$ after placebo or MP administration. Self-reports of "tired" were strongly correlated with those of "sleepiness," so we did not report correlations for this descriptor. For analysis purposes, we averaged the values for the placebo condition and used the values obtained at $90 \mathrm{~min}$ after MP, which is when the peak MP plasma concentration occurred.

$S D$ and rested wakefulness (non-sleep deprivation) procedures. Subjects were kept overnight at Brookhaven National Laboratory before their scheduled SD or RW session to ensure that subjects stayed awake for the SD session (1 night of sleep deprivation) or had a good night rest for the RW session (mean duration of sleep, $7 \pm 1 \mathrm{~h}$ ) conditions. A research assistant remained with them throughout the night to ensure that they did not fall asleep for the SD or that they slept properly for the RW session. On the day of the RW session, the subjects were awakened at 7:00 A.M. and brought to the imaging suite where a nurse remained with them to ensure that they stayed awake throughout the study. No food was given after midnight, and caffeinated beverages were discontinued for $24 \mathrm{~h}$ before the study.
Table 1. Self-reports of alertness and sleepiness for the RW and SD sessions after placebo and after MP

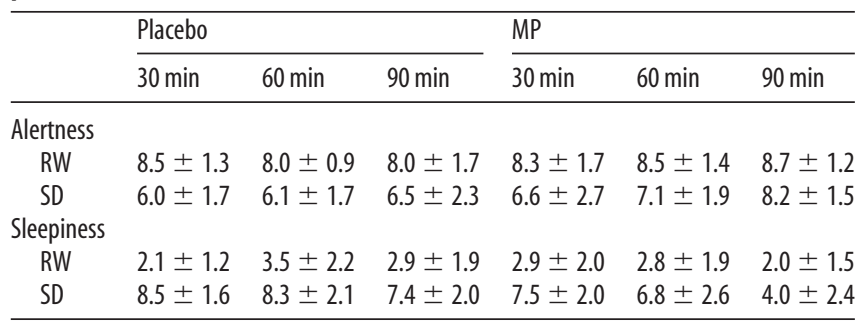

Values correspond to means \pm SDs.

Table 2. Measures of $D 2 R$ availability $\left(B P_{N D}\right.$ ) after placebo and after MP for the $R W$ and the SD sessions and $p$ values for comparisons between PL and MP (repeated ANOVA)

\begin{tabular}{|c|c|c|c|c|c|c|}
\hline & \multicolumn{3}{|l|}{ RW } & \multicolumn{3}{|l|}{ SD } \\
\hline & PL & MP & $\begin{array}{l}\text { PL versus } \\
\text { MP }\end{array}$ & PL & MP & $\begin{array}{l}\text { PL versus } \\
\text { MP }\end{array}$ \\
\hline & $2.43 \pm 0.35$ & $2.30 \pm 0.35$ & 0.06 & $2.48 \pm 0.31$ & $2.38 \pm 0.31$ & NS \\
\hline PUT & $3.07 \pm 0.37$ & $2.81 \pm 0.47$ & 0.005 & $3.09 \pm 0.28$ & $2.85 \pm 0.34$ & 0.003 \\
\hline VS & $2.95 \pm 0.37^{*}$ & $2.73 \pm 0.41$ & 0.0002 & $2.80 \pm 0.37^{*}$ & $2.63 \pm 0.37$ & 0.06 \\
\hline
\end{tabular}

${ }^{*} p<0.05$ for the comparison of the placebo measures between the RW and SD sessions. CDT, Caudate; PUT, putamen; VS, ventral striatum; $\mathrm{PL}$, placebo. Values correspond to means and standard deviations.

Imaging. PET studies were done with a Siemens HR + tomograph (resolution $4.5 \times 4.5 \times 4.5 \mathrm{~mm}$ full-width at half-maximum). Each subject served as his own control and was tested on 2 separate days; $1 \mathrm{~d}$ after RW and another after 1 night of SD. The order of the sessions (RW or $\mathrm{SD}$ ) was randomized to control for order effects. On each day, subjects underwent two sets of scans: the first scan was performed after placebo, and the second scan was performed $2 \mathrm{~h}$ later and $60 \mathrm{~min}$ after MP administration (40 mg, p.o.). The placebo scans were performed between 10:00 A.M. and 11:00 AM, and the MP scans between 12:00 P.M. and 1:00 P.M.; 3-4 h (placebo) and 5-6 h (MP) after awakening for the RW session, and 27-28 h (placebo) and 29-30 h (MP) after awakening for the SD session. Sequential dynamic scans were started immediately after intravenous injection of $4-10 \mathrm{mCi}$ of $\left[{ }^{11} \mathrm{C}\right]$ raclopride (specific activity, $>0.25 \mathrm{Ci} / \mu \mathrm{mol}$ at time of injection) for a total of $60 \mathrm{~min}$ as previously described (Volkow et al., 1994). The doses of $\left[{ }^{11} \mathrm{C}\right]$ raclopride injected did not differ among the four different conditions.

To ensure that subjects would not fall asleep during the study, they were asked to keep their eyes open, and a nurse remained by their side to ensure compliance. If the subjects closed their eyes, the nurse would ask them to open them again.

Image analysis and statistics. Regions of interest (ROIs) were obtained directly from the $\left[{ }^{11} \mathrm{C}\right]$ raclopride images as previously described (Volkow et al., 1994, 1995). Briefly, we identified and selected the ROI on summed images (dynamic images taken from 10 to $54 \mathrm{~min}$ ) that were resliced along the intercommisural plane (anterior commissure-posterior commissure line). The ROI is based on a template that uses geometrical shapes of the same size across subjects and conditions. For the caudate, putamen, ventral striatum (VS), and cerebellum, the ROIs were extracted on 4,3,1, and 2 planes, respectively, and right and left regions were delineated. These regions were then projected to the dynamic scans to obtain concentrations of $\mathrm{C}-11$ vs time, which were used to calculate the distribution volumes using a graphical analysis technique for reversible systems that does not require arterial blood sampling (Logan et al., 1996). We computed the ratio of the distribution volume in striatal regions to that in the cerebellum to obtain the nondisplaceable binding potential $\left(\mathrm{BP}_{\mathrm{ND}}\right)$, which was used as a quantification of $\mathrm{D} 2 / \mathrm{D} 3 \mathrm{R}$ availability.

Differences on the $\mathrm{BP}_{\mathrm{ND}}$ between RW and $\mathrm{SD}$ were tested with repeated ANOVAs (left and right regions were averaged into one measure). Pearson product moment correlations were used to assess the association between the changes in $\mathrm{BP}_{\mathrm{ND}}(\mathrm{SD}-\mathrm{RW} / \mathrm{RW} \times 100)$ and the changes in the behavioral measures ( $S D-R W$ ). To test the main hypotheses of the 


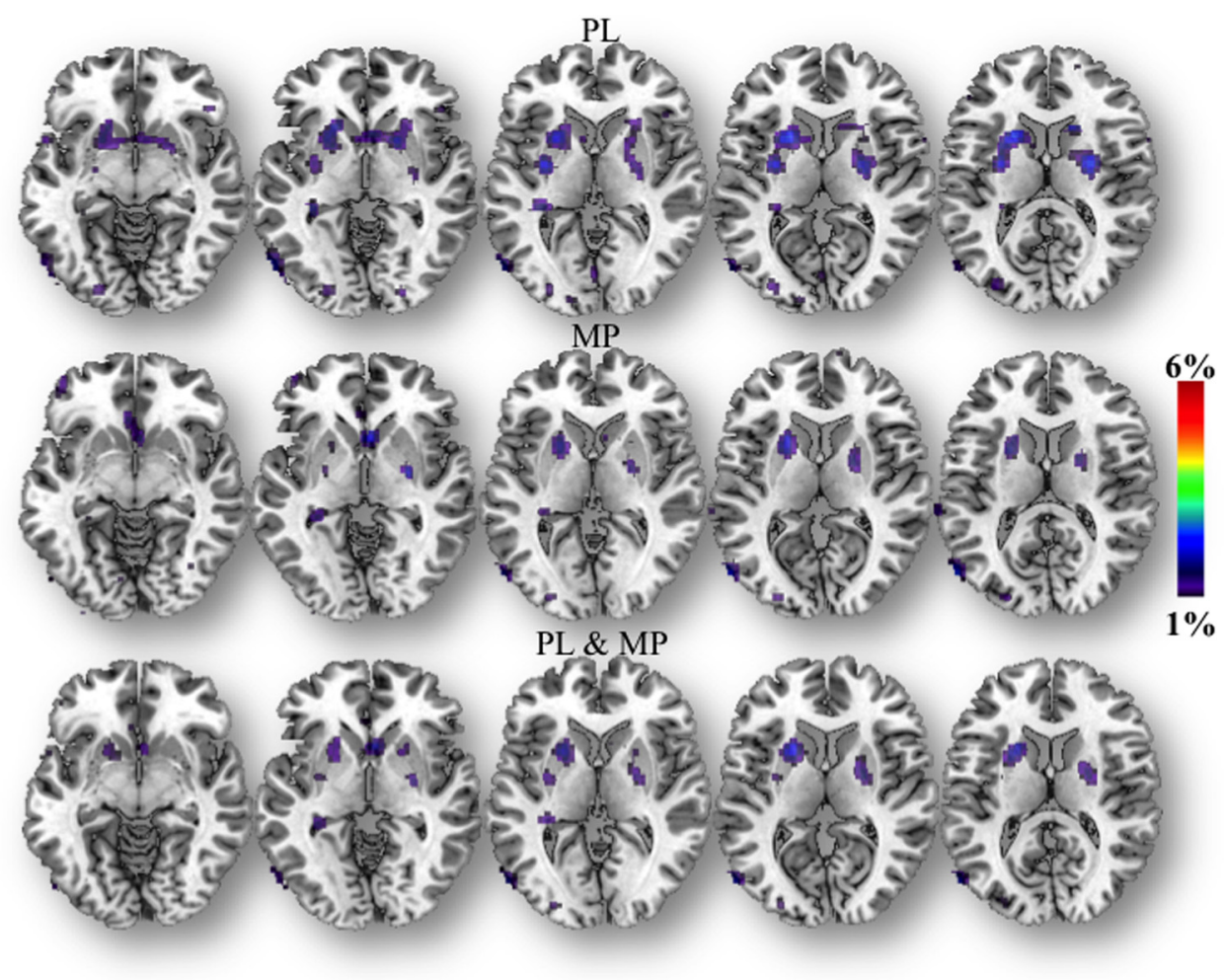

Figure 1. SPM results showing the regions where $D 2 / D 3 R B P_{N D}$ was greater for $R W$ than for $S D$ (RW $>S D ; p<0.005$ uncorrected), both for the placebo and the MP conditions, and for both combined.

study, namely, that $\mathrm{SD}$ would decrease $\mathrm{BP}_{\mathrm{ND}}$ and that these differences would be associated with increased sleepiness and reduced alertness, and that $\mathrm{MP}$ would reduce $\mathrm{BP}_{\mathrm{ND}}$ to a greater extent in $\mathrm{SD}$ than for $\mathrm{RW}$, we set significance at $p<0.05$.

We also analyzed the $\mathrm{BP}_{\mathrm{ND}}$ images using statistical parametric mapping (SPM), which enabled us to make comparisons on a voxel-by-voxel basis (Friston et al., 1995). Repeated ANOVAs were performed to compare the RW and SD sessions (both for placebo and MP), to assess the effects of MP on $\mathrm{BP}_{\mathrm{ND}}$ (both for RW and SD), and to compare whether $\mathrm{MP}$-induced changes in $\mathrm{BP}_{\mathrm{ND}}$ differed for the RW and SD sessions. Significance was set at $p<0.005$ uncorrected, a cluster threshold of $>100$ voxels. Since age affects D2/D3R availability, we also assessed the correlation analysis among age, the changes in $\mathrm{BP}_{\mathrm{ND}}$ with $\mathrm{SD}$, and the changes with MP.

Microdialysis experiments. Male, Sprague Dawley rats (8 weeks old) kept on a reverse light cycle were divided into two groups: one to assess the effects of SD $(n=6)$, and the other to serve as controls $(n=$ 6 ). Rats in the SD group underwent paradoxical sleep deprivation for $16 \mathrm{~h}$ (5:00 P.M. to 9:00 A.M.) using the single platform-on-water method ("flower pot") (Machado et al., 2004; Kitka et al., 2009), whereas control rats were left overnight in a similar apparatus and setup but were placed on a larger platform $(10 \mathrm{~cm}$ diameter $)$ that allowed them to sleep. Microdialysis measurements in the nucleus accumbens (core) were then obtained from 10:00 A.M. to 4:00 P.M., and samples were obtained every $20 \mathrm{~min}$ as previously described (Schiffer et al., 2003). At noon, animals were intravenously injected with MP (1 mg) via a jugular vein catheter. Procedures for anesthesia and jugular vein catheterization were as previously published (Thanos et al., 2011). We averaged the measures obtained before MP administration to compare "baseline measures" between paradoxical sleep-deprived and control rats with unpaired $t$ tests (two tailed). We computed the percentage change from this "baseline measure" and compared the peak DA increases induced by MP $(20-40)$ between paradoxical sleep-deprived and control rats with $t$ tests (two tailed). Experiments were conducted by a facility accredited by the Association for Assessment and Accreditation of Laboratory Animal Care
Table 3. SPM results for the locations of clusters where D2R BP ${ }_{N D} R W>S D$ (PL and $M P$ ), and for the location of the cluster where $D 2 R B_{N D}$ placebo $>M P$ for the $R W$ sessions and where $D 2 R$ BP ${ }_{\mathrm{ND}}$ placebo $>M P$ for the $S D$ session

\begin{tabular}{lrrrlllll}
\hline Region & $x$ & $y$ & $z$ & $p F W E$ & $p F D R$ & $t$ & $z$ & $p_{\text {uncorrected }}$ \\
\hline RW $>$ SD & & & & & & & & \\
$\quad$ Putamen & 20 & -2 & 10 & 0.026 & 0.013 & 2.77 & 2.67 & 0.004 \\
$\quad \begin{array}{l}\text { Putamen } \\
\quad \text { Caudate }\end{array}$ & -20 & 12 & 8 & 0.038 & 0.017 & 2.58 & 2.5 & 0.006 \\
$\begin{array}{l}\text { Placebo }>\text { MP for RW } \\
\quad\end{array}$ & 4 & 14 & -6 & 0.001 & 0.001 & 3.9 & 3.66 & 0.0001 \\
$\quad \begin{array}{l}\text { Putamen } \\
\quad \text { Putamen }\end{array}$ & 34 & -6 & 2 & 0 & 0 & 4.55 & 4.14 & 0.0001 \\
$\quad-26$ & -4 & 2 & 0 & 0 & 4.94 & 4.49 & 0.0001 \\
$\quad$ Caudate & 10 & 12 & -6 & 0.009 & 0.007 & 3.21 & 3.06 & 0.001 \\
$\quad$ Thalamus & 10 & -4 & 4 & 0.111 & 0.089 & 2 & 1.97 & 0.025 \\
$\begin{array}{l}\text { Placebo }>\text { MP for SD } \\
\quad \text { Putamen }\end{array}$ & & & & & & & & \\
$\quad$ Putamen & 30 & -6 & 2 & 0 & 0.001 & 3.77 & 3.55 & 0.0001 \\
$\quad$ Caudate & -24 & -4 & 0 & 0 & 0 & 5.18 & 4.67 & 0.0001 \\
$\quad$ Thalamus & 4 & 14 & -6 & 0.03 & 0.019 & 2.7 & 2.61 & 0.0001 \\
& 0 & 0 & 2 & 0.071 & 0.043 & 2.26 & 2.2 & 0.014 \\
\hline
\end{tabular}

Small volume corrections: 8-mm-diameter sphere centered at the MNI coordinates (left to right for $X$, anterior to posterior for $y$, and superior to inferior for $z$ ). $p F W E=$ significance after correction for family wise error; $\mathrm{pFDR}=$ significance after correction for false discovery rate.

under the oversight of the Institutional Animal Care and Use Committee of Brookhaven National Laboratory.

\section{Results}

\section{Behavioral effects of SD with or without MP and plasma} levels

Self-reports of alertness were significantly reduced and those of sleepiness were increased after SD (Table 1). MP significantly increased alertness and reduced sleepiness when given after SD, but not when given after RW (Table 1).

The concentration of MP in plasma did not differ between the RW and the SD sessions, neither for the $60 \mathrm{~min}(6.2 \pm 7$ and $5.1 \pm$ 

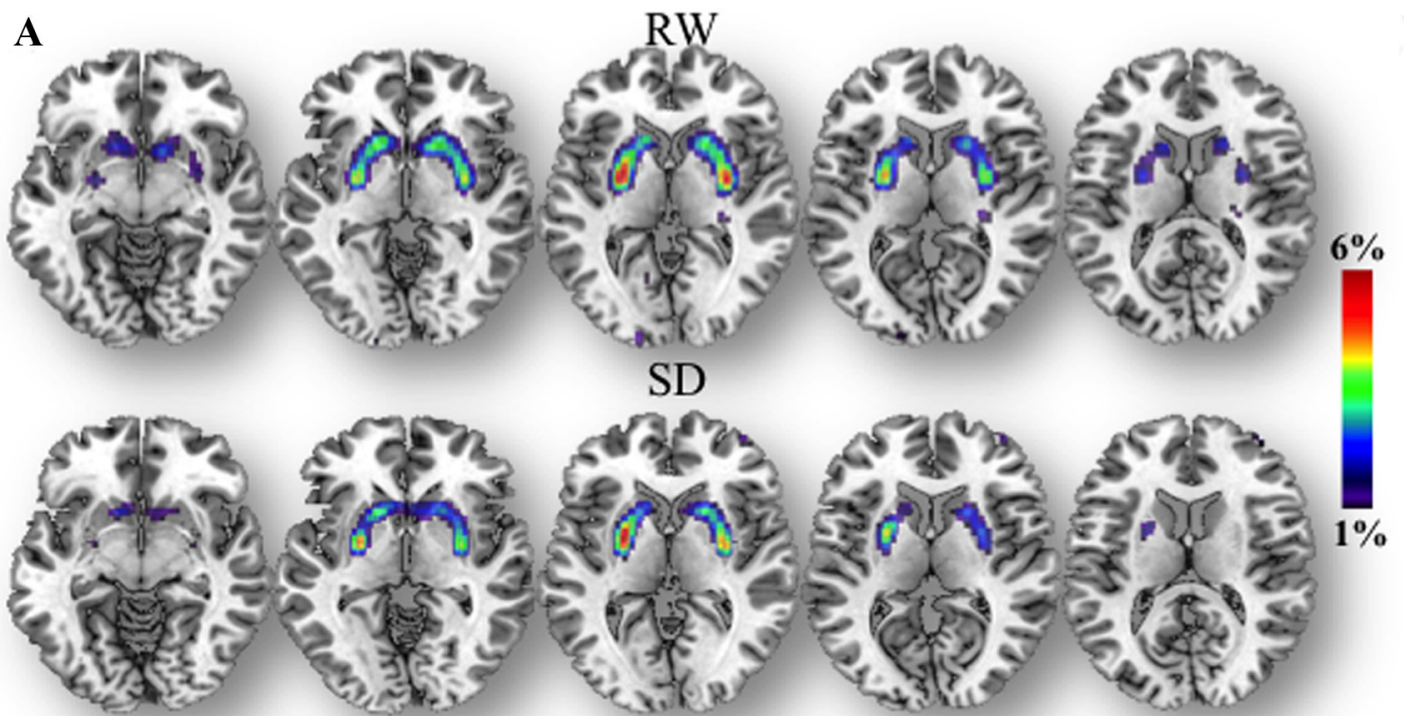

B
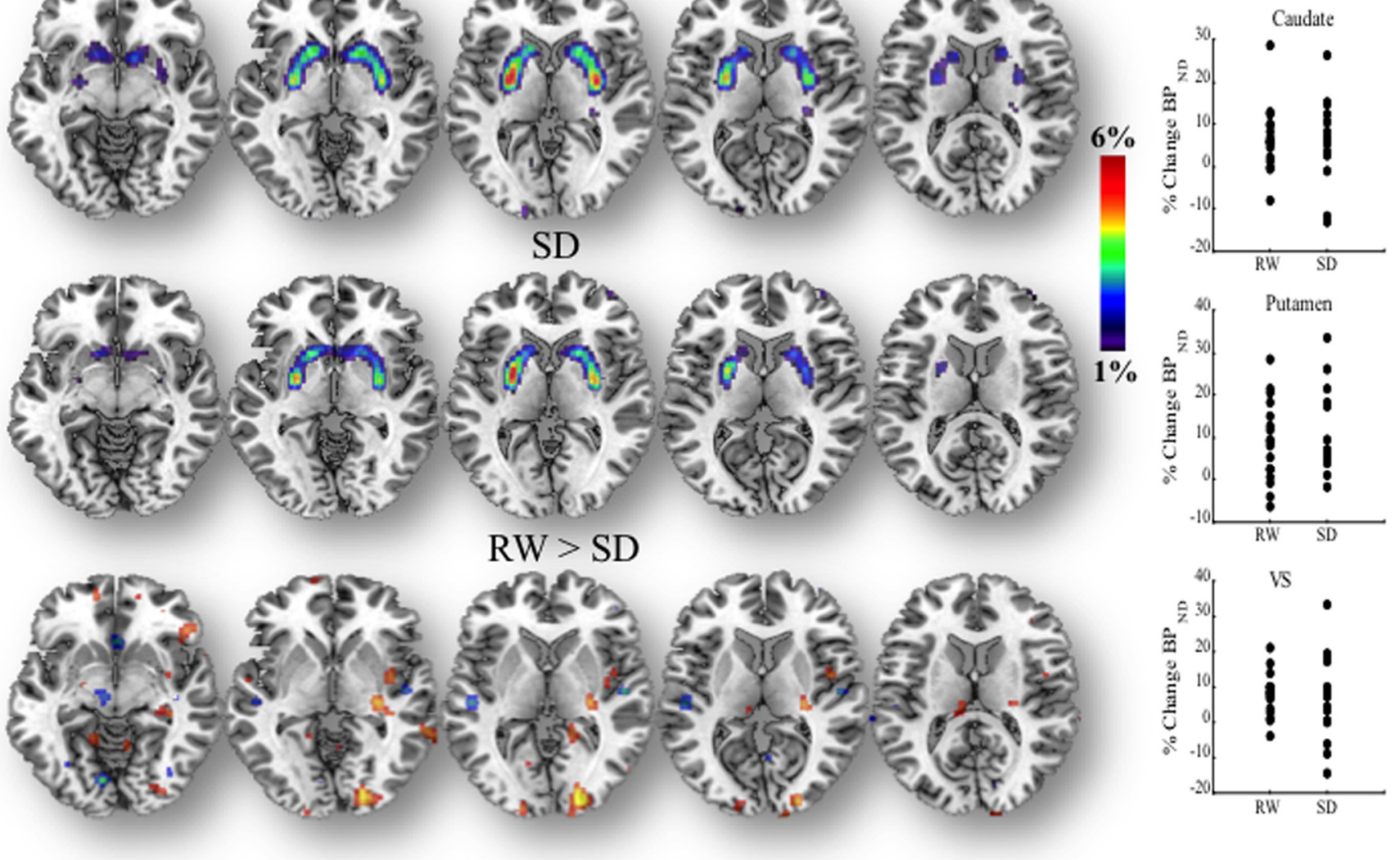

Figure 2. A, SPM results showing the regions where D2/D3R BP was greater for placebo than for MP [placebo (PL) $>M P ; p<0.005$ uncorrected], which reflect MP-induced DA increased, both for the RW and the SD conditions and for the results for the comparison of MP-induced changes between RW and SD (RW $>S D ; p<0.05$ uncorrected). Neither the comparison of MP-induced changes for the contrast $\mathrm{RW}>\mathrm{SD}$ nor that for SD $>$ RW were significant. $\boldsymbol{B}$, Scattergrams for the percentage change in $\mathrm{BP}_{\mathrm{ND}}$ with MP (with respect to placebo) both for RW and SD in caudate, putamen, and VS.

$4 \mathrm{ng} / \mathrm{ml}$; respectively) nor the 90 min plasma measures $(9.8 \pm 8$ and $9.9 \pm 8 \mathrm{ng} / \mathrm{ml}$; respectively).

\section{Effects of SD on D2/D3R availability}

The ROI analysis showed that D2/D3R availability was significantly lower in the VS in SD than in RW, but it did not differ in caudate or putamen (Table 2). The SPM analysis (RW $>$ SD) corroborated the decreases in D2/D3R during SD in VS but also revealed decreases in clusters that included regions in caudate and putamen (Fig. 1; Table 3).

\section{Effects of MP on D2/D3R availability}

The ROI analysis revealed that MP decreased D2/D3R in striatal regions both for the RW and the SD conditions. Moreover, the magnitude of these changes did not differ between the RW and the SD conditions (Table 2). Specifically, the decrease in D2/D3R availability for RW and SD, respectively, were as follows: caudate, $4.9 \pm 11 \%$ and $4.6 \pm 11 \%$; putamen, $8.8 \pm 11 \%$ and $7.8 \pm 10 \%$; and VS, $7.1 \pm 6 \%$ and $9.5 \pm 12 \%$. SPM corroborated that MPinduced significant decreases in D2/D3R availability in striatum both for the RW and the SD conditions, and also failed to reveal significant differences in MP-induced changes between the RW and the SD sessions (Fig. 2; Table 3). Note that neither the SPM comparison of MP-induced DA changes for SD $>\mathrm{RW}$ or for $\mathrm{RW}>\mathrm{SD}$ were significant.
Correlation between changes in D2/D3R and self-reports and effects of age

The decreases in $\mathrm{D} 2 / \mathrm{D} 3 \mathrm{R}$ with $\mathrm{SD}$ in VS (percentage change from RW) were correlated with the decreases in self-reports of alertness $(r=0.44, p<0.05)$ and with the increases in sleepiness $(r=$ $0.50, p<0.03$ ) observed during SD (Fig. $3 A$ ).

The pattern of correlations between MP-induced decreases in D2/D3R availability (percentage change from placebo) and the changes in self-reports observed with MP during SD were in the opposite direction to those observed for the changes between RW and SD (for the placebo measures as reported in the paragraph above). Specifically, MP-induced decreases in D2/D3R availability were associated with increases in self-reports of alertness in caudate $(r=-0.77, p<0.0001)$ and putamen $(r=-0.50, p<$ $0.03)$, and with decreases in sleepiness in caudate $(r==-0.52$, $p<0.02)$ and putamen $(r=-0.74, p<0.001)$ (Fig. 3B).

Aging was negatively correlated with the baseline measures of D2/D3R availability for RW (putamen, $r=0.52, p<0.05$; VS, $r=$ $0.64, p<0.005$ ), but not for SD. However, neither the correlation between aging and the effects of SD on D2/D3R availability nor the correlation between aging and the effects of MP on D2/D3R availability were significant (data not shown).

\section{Microdialysis experiments in rats}

The DA measures in NAc taken after 1 night of paradoxical sleep deprivation before MP (baseline measures averaged over $2 \mathrm{~h}$ ) did 

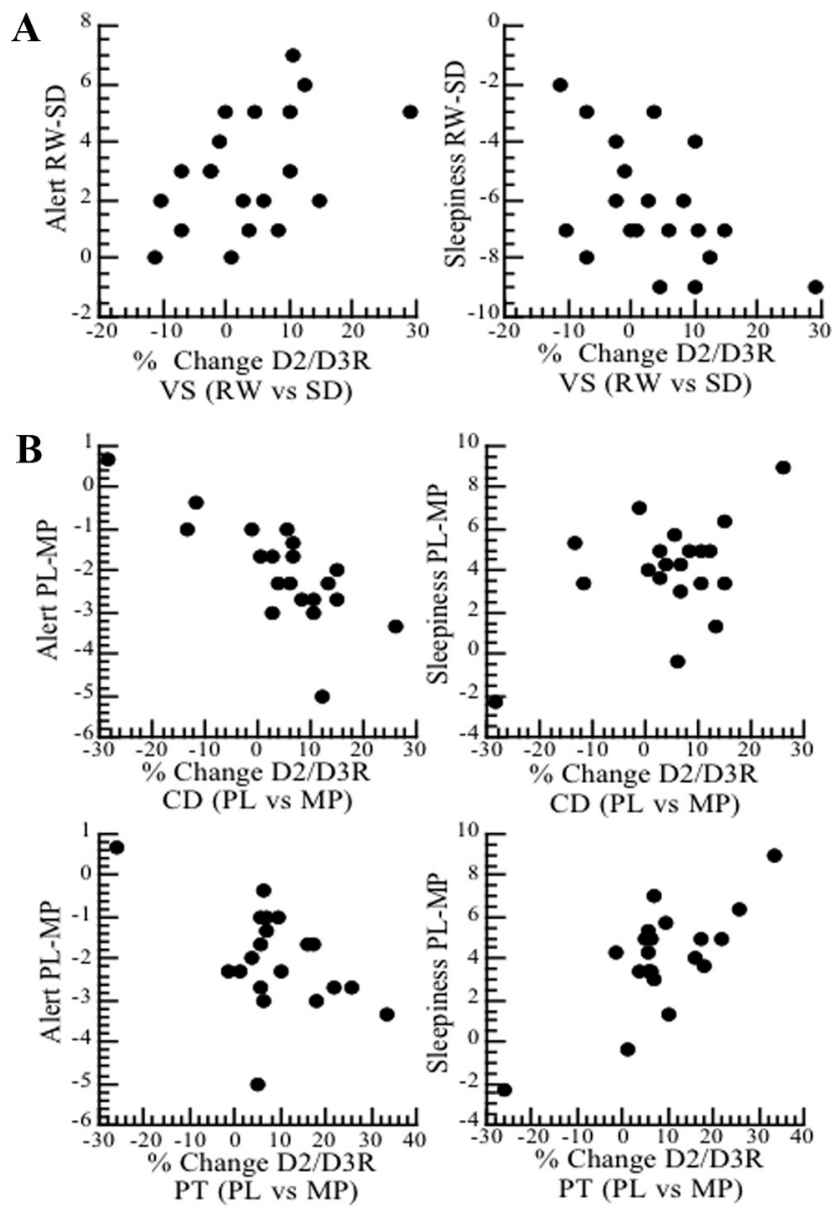

Figure 3. Correlations between changes in D2/D3R BP and changes in self-reports of alertness and sleepiness. $A$, Correlations for the D2R changes in VS and self-reports between RW and SD (placebo measures). $\boldsymbol{B}$, Correlations for the D2R changes in caudate (CD) and putamen (PT) and self-reports between placebo (PL) and MP for the SD condition.

not differ between the paradoxical sleep-deprived rats and the control rats $(p=0.63)$. The comparisons of the DA increases induced by MP (percentage change from baseline measures) did not differ between the group of paradoxical sleep-deprived rats $(128 \% \pm 48)$ and the controls $(132 \% \pm 31)$ (Fig. 4).

\section{Discussion}

Here we replicate our prior findings of a reduction in D2/D3R availability in ventral striatum with SD that was associated with reduced alertness. However, we did not find the differences in MP-induced changes in striatal D2/D3 availability between RW and SD that we had initially hypothesized. This leads us to question our prior interpretation that the reductions in D2/D3R availability with SD reflected DA increases (competing for binding with $\left[{ }^{11} \mathrm{C}\right]$ raclopride) since such increases would have triggered larger DA increases with MP during SD than during RW. This is because MP blocks the DAT, interfering with the reuptake of DA into the terminal; thus, the DA increases for an equivalent level of DAT blockade reflect the amount of DA released (Volkow et al., 2002a). Moreover, our microdialysis results also showed no increases in DA after 1 night of paradoxical sleep deprivation and no differences in MP-induced DA in NAc between paradoxical sleep-deprived and control rats. Thus, based on these findings we now interpret the reduction in D2/D3 availability in VS with SD as a reflection $\mathrm{D} 2 / \mathrm{D} 3 \mathrm{R}$ downregulation.

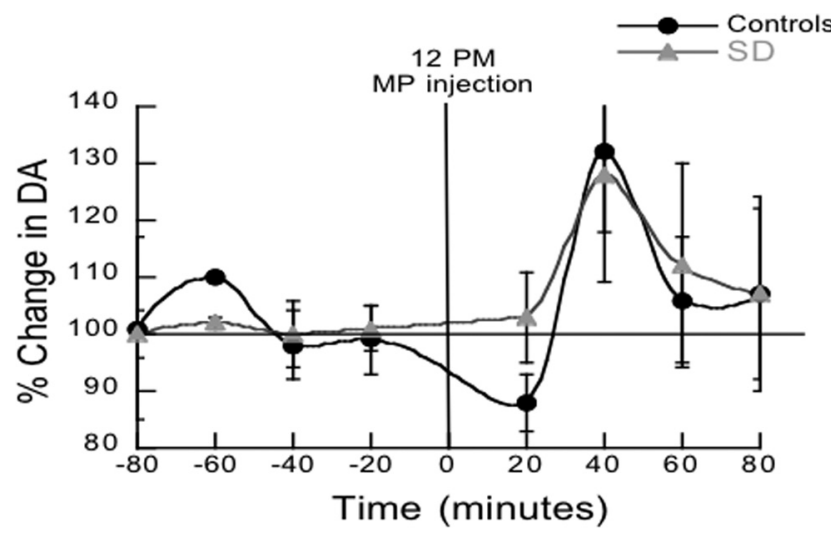

Figure 4. Results for the microdialysis experiments measuring extracellular DA levels in nucleus accumbens between 10:00 A.M. and 4:00 P.M. both for a group of rats (SD) subjected the preceding night to paradoxical sleep deprivation (placed on a small platform surrounded by water) and in a group of rats (controls) subjected to a similar environment during the night except that they were placed on a larger a platform that allowed them to sleep. Values correspond to means and standard errors.

Indeed, the opposite pattern of the correlations observed between the decreases in D2/D3R and self-reports with SD (associated with reduced alertness and increased sleepiness), than with MP (associated with increased alertness and reduced sleepiness), suggests that they reflect different physiological processes mediating the D2/ D3R decreases with SD (D2/D3R downregulation) than with MP (DA increases). MP is known to increase DA in striatum (Kuczenski and Segal, 1997; Huff and Davies, 2002; Volkow et al., 2005), an effect that is consistent with our imaging and microdialysis results. However, there is no reported preclinical evidence of DA increases in striatum following SD, and our microdialysis studies failed to show any DA increases. Downregulation of D2/D3R by SD could explain why reductions in D2/D3R availability were associated with reduced alertness since this would result in reduced D2R signaling. Evidence of the role of D2R signaling in the arousing effects of DA is shown by the decreased wakefulness (Qu et al., 2010) and the insensitivity to the wake-enhancing effects of modafinil observed in D2R knockout mice (Qu et al., 2008). In contrast, the DA increases induced by MP would help counteract the decreased signaling from D2/ D3R downregulation, thereby increasing wakefulness during SD.

The internalization of DA receptors allows neurons to readjust their excitability (von Zastrow, 2003; Iizuka et al., 2007) and is necessary for ensuring accurate neurotransmission (Gainetdinov et al., 2004). In fact, experiments show that with prolonged DA stimulation the D2Rs downregulate (Bartlett et al., 2005), and in flies D2R downregulation underlies the light's suppression of the wake-promoting effects of DA (Shang et al., 2011), corroborating a role of D2R internalization in modulating wakefulness. PET studies in rodents have given evidence that D2/D3R internalization might explain why amphetamine-induced decreases in striatal $\left[{ }^{11} \mathrm{C}\right]$ raclopride binding are more protracted than the amphetamine-induced DA increases (Sun et al., 2003; Ginovart et al., 2004). Specifically, in mice lacking $\beta$-arrestin-2 (arrestin3), which is necessary for D2R internalization (Skinbjerg et al., 2009), the decreases in striatal binding of a D2R agonist PET ligand $\left(\left[{ }^{11} \mathrm{C}\right] \mathrm{MNPA}\right)$ or a D2R antagonist ([ $\left.{ }^{18} \mathrm{~F}\right]$ fallypride) induced by amphetamine recovered $4 \mathrm{~h}$ after administration, whereas the levels remained decreased in wild-type mice (Skinbjerg et al., 2010).

Adenosine, through $\mathrm{A}_{2 \mathrm{~A}}$ receptors, regulates $\mathrm{D} 2 \mathrm{R}$ internalization (Hillion et al., 2002), apparently by facilitating the binding of 
$\beta$-arrestin-2 to the $\mathrm{A}_{2 \mathrm{~A}}$-D2 receptor heteromer (Borroto-Escuela et al., 2011). This is noteworthy since increases in extracellular adenosine levels drive the pressure to sleep with SD (PorkkaHeiskanen et al., 1997), which is partly mediated through $\mathrm{A}_{2 \mathrm{~A}}$ receptors (Hayaishi et al., 2004). Indeed, the adenosine receptor antagonist caffeine increases wakefulness (Biaggioni et al., 1991; Schwierin et al., 1996) via its $\mathrm{A}_{2 \mathrm{~A}}$ antagonist effects (Huang et al., 2005) in the NAc (Lazarus et al., 2011). Interestingly, in healthy controls, caffeine was shown to increase D2/D3R availability in VS (measured with PET and $\left[{ }^{11} \mathrm{C}\right]$ raclopride), an effect that was associated with decreased tiredness (Kaasinen et al., 2004). Note that this association is akin to our findings with $\mathrm{SD}$, for which the opposite effect on D2/D3R in VS (decrease) was associated with the opposite effects in tiredness (increased sleepiness). Since caffeine modulates DA signaling in part by its antagonism of $\mathrm{A}_{2 \mathrm{~A}}$ receptors (Ferre et al., 2008), caffeine-induced D2/D3R increases in VS would be consistent with caffeine's antagonism of $\mathrm{A}_{2 \mathrm{~A}^{-}}$ mediated D2R internalization. Indeed, $A_{2 A}$ receptor knock-out mice show increased D2R levels in striatum (Dassesse et al., 2001). However $A_{1}$ receptors are also involved in the effects of SD (Thakkar et al., 2003), and upregulation of $A_{1}$ receptors has been documented during SD both in humans and rodents (Elmenhorst et al., 2007, 2009).

The downregulation of D2/D3R in VS under SD conditions, in addition to contributing to reduced wakefulness, could also affect other behaviors. Specifically, DA stimulation of D2/D3R in VS is implicated in attention (Volkow et al., 2012), and thus D2/D3R downregulation could contribute to the inattentiveness observed with SD (Durmer and Dinges, 2005; Tomasi et al., 2009) and explain our prior findings of an association between decreases in D2/D3R availability and impairments in visual attention with SD (Volkow et al., 2009). Also D2R in VS modulate risk-taking propensity (Linnet et al., 2011), and thus D2/D3R reductions with SD could facilitate the engagement in risky behaviors characteristic of SD (McKenna et al., 2007). Finally, lower $\mathrm{D} 2 \mathrm{R}$ in VS is associated with a greater risk for compulsive drug consumption (Dalley et al., 2007) and could contribute to relapse in sleep-deprived substance abusers (Gillin, 1998).

Here, we interpret the reductions in $\left[{ }^{11} \mathrm{C}\right]$ raclopride binding in VS with SD as reflecting a downregulation of D2/D3R, but they could also reflect decreases in receptor affinity. However, this is unlikely since a decrease in D2/D3R affinity would have led to a reduced decrease in $\mathrm{BP}_{\mathrm{ND}}$ with $\mathrm{MP}$ during the $\mathrm{SD}$ session, which we did not observe.

Our results differ from those from a recent study in rodents that reported that paradoxical sleep deprivation was associated with increases in D3R but no changes in D2R binding in striatum (Lim et al., 2011), which is distinct from our finding of reductions in D2/D3R with SD. The reasons for this discrepancy are unclear but could reflect differences between the paradoxical SD (rats) and the total SD (humans) models. Interestingly, in our results the findings we obtained with total SD in the clinical PET studies were corroborated by our microdialysis studies in the rat with paradoxical SD. A further limitation for our clinical studies was that they could not separately assess the effects of SD on D2R versus D3R binding since raclopride binds to both. Future studies using PET ligands that only bind to D2R or D3R are needed to address this.

A confound for our clinical studies is the potential influence that the mental state can have on an individual's baseline measures of $\mathrm{BP}_{\mathrm{ND}}$ (Yoder et al., 2008) and on the magnitude of MPinduced DA changes (Volkow et al., 1994). Also, we did not record how many times during the scans the nurse had to remind subjects to keep their eyes open, and thus we cannot evaluate whether these interactions affected the $\mathrm{BP}_{\mathrm{ND}}$ measures.

This study corroborates a reduction in D2/D3R availability with SD in VS that was associated with reduced alertness. In contrast, MP-induced decreases in striatal D2/D3R availability (secondary to DA increases), which did not differ between RW and SD, were associated with increased alertness. This suggests that the reductions in D2/D3R induced by SD reflect a different physiological mechanism (downregulation of D2/D3R) than those mediating MP effects (increased DA). We also provide evidence that in the human brain under conditions of SD the increases in DA triggered by MP are associated with its alerting and awakening effects.

\section{References}

Arnulf I, Konofal E, Merino-Andreu M, Houeto JL, Mesnage V, Welter ML, Lacomblez L, Golmard JL, Derenne JP, Agid Y (2002) Parkinson's disease and sleepiness: an integral part of PD. Neurology 58:1019-1024.

Baldessarini RJ (1990) Drugs and the treatment of psychiatric disorders: depression and anxiety disorders. In: Goodman and Gilmans's the pharmacological basis of therapeutics (Goodman Gilman AG, Rail TW, Nies AS, Taylor P, eds), pp 447-484. New York: Pergamon.

Bartlett SE, Enquist J, Hopf FW, Lee JH, Gladher F, Kharazia V, Waldhoer M, Mailliard WS, Armstrong R, Bonci A, Whistler JL (2005) Dopamine responsiveness is regulated by targeted sorting of D2 receptors. Proc Natl Acad Sci U S A 102:11521-11526.

Biaggioni I, Paul S, Puckett A, Arzubiaga C (1991) Caffeine and theophylline as adenosine receptor antagonists in humans. J Pharmacol Exp Ther 258:588-593.

Borroto-Escuela DO, Romero-Fernandez W, Tarakanov AO, Ciruela F, Agnati LF, Fuxe K (2011) On the existence of a possible A2A-D2-betaArrestin2 complex: A2A agonist modulation of D2 agonist-induced betaarrestin2 recruitment. J Mol Biol 406:687-699.

Dalley JW, Fryer TD, Brichard L, Robinson ES, Theobald DE, Lääne K, Peña Y, Murphy ER, Shah Y, Probst K, Abakumova I, Aigbirhio FI, Richards HK, Hong Y, Baron JC, Everitt BJ, Robbins TW (2007) Nucleus accumbens D2/3 receptors predict trait impulsivity and cocaine reinforcement. Science 315:1267-1270

Dassesse D, Massie A, Ferrari R, Ledent C, Parmentier M, Arckens L, Zoli M, Schiffmann SN (2001) Functional striatal hypodopaminergic activity in mice lacking adenosine A(2A) receptors. J Neurochem 78:183-198.

Durmer JS, Dinges DF (2005) Neurocognitive consequences of sleep deprivation. Semin Neurol 25:117-129.

Elmenhorst D, Meyer PT, Winz OH, Matusch A, Ermert J, Coenen HH, Basheer R, Haas HL, Zilles K, Bauer A (2007) Sleep deprivation increases A1 adenosine receptor binding in the human brain: a positron emission tomography study. J Neurosci 27:2410-2415.

Elmenhorst D, Basheer R, McCarley RW, Bauer A (2009) Sleep deprivation increases $\mathrm{A}(1)$ adenosine receptor density in the rat brain. Brain Res 1258:53-58

Ferre S, Ciruela F, Borycz J, Solinas M, Quarta D, Antoniou K, Quiroz C, Justinova Z, Lluis C, Franco R, Goldberg SR (2008) Adenosine A1-A2A receptor heteromers: new targets for caffeine in the brain. Front Biosci 13:2391-2399.

Friston KJ, Holmes AP, Poline JB, Grasby PJ, Williams SC, Frackowiak RS, Turner R (1995) Analysis of fMRI time-series revisited. Neuroimage 2:45-53.

Gainetdinov RR, Premont RT, Bohn LM, Lefkowitz RJ, Caron MG (2004) Desensitization of $\mathrm{G}$ protein-coupled receptors and neuronal functions. Annu Rev Neurosci 27:107-144.

Gillin JC (1998) Are sleep disturbances risk factors for anxiety, depressive and addictive disorders? Acta Psychiatr Scand Suppl 393:39-43.

Ginovart N, Wilson AA, Houle S, Kapur S (2004) Amphetamine pretreatment induces a change in both D2-Receptor density and apparent affinity: a [11C]raclopride positron emission tomography study in cats. Biol Psychiatry 55:1188-1194.

Hayaishi O, Urade Y, Eguchi N, Huang ZL (2004) Genes for prostaglandin d synthase and receptor as well as adenosine A2A receptor are involved in the homeostatic regulation of nrem sleep. Arch Ital Biol 142:533-539.

Hillion J, Canals M, Torvinen M, Casado V, Scott R, Terasmaa A, Hansson A, 
Watson S, Olah ME, Mallol J, Canela EI, Zoli M, Agnati LF, Ibanez CF, Lluis C, Franco R, Ferre S, Fuxe K (2002) Coaggregation, cointernalization, and codesensitization of adenosine $\mathrm{A} 2 \mathrm{~A}$ receptors and dopamine $\mathrm{D} 2$ receptors. J Biol Chem 277:18091-18097.

Huang ZL, Qu WM, Eguchi N, Chen JF, Schwarzschild MA, Fredholm BB, Urade Y, Hayaishi O (2005) Adenosine A2A, but not A1, receptors mediate the arousal effect of caffeine. Nat Neurosci 8:858-859.

Huff JK, Davies MI (2002) Microdialysis monitoring of methylphenidate in blood and brain correlated with changes in dopamine and rat activity. J Pharm Biomed Anal 29:767-777.

lizuka Y, Sei Y, Weinberger DR, Straub RE (2007) Evidence that the BLOC-1 protein dysbindin modulates dopamine D2 receptor internalization and signaling but not D1 internalization. J Neurosci 27:12390-12395.

Kaasinen V, Aalto S, Någren K, Rinne JO (2004) Dopaminergic effects of caffeine in the human striatum and thalamus. Neuroreport 15:281-285.

Killgore WD, Rupp TL, Grugle NL, Reichardt RM, Lipizzi EL, Balkin TJ (2008) Effects of dextroamphetamine, caffeine and modafinil on psychomotor vigilance test performance after $44 \mathrm{~h}$ of continuous wakefulness. J Sleep Res 17:309-321.

Kitka T, Katai Z, Pap D, Molnar E, Adori C, Bagdy G (2009) Small platform sleep deprivation selectively increases the average duration of rapid eye movement sleep episodes during sleep rebound. Behav Brain Res 205:482-487.

Kuczenski R, Segal DS (1997) Effects of methylphenidate on extracellular dopamine, serotonin, and norepinephrine: comparison with amphetamine. J Neurochem 68:2032-2037.

Lazarus M, Shen HY, Cherasse Y, Qu WM, Huang ZL, Bass CE, WinskySommerer R, Semba K, Fredholm BB, Boison D, Hayaishi O, Urade Y, Chen JF (2011) Arousal effect of caffeine depends on adenosine A2A receptors in the shell of the nucleus accumbens. J Neurosci 31:10067-10075.

Lim MM, Xu J, Holtzman DM, Mach RH (2011) Sleep deprivation differentially affects dopamine receptor subtypes in mouse striatum. Neuroreport 22:489-493.

Linnet J, Møller A, Peterson E, Gjedde A, Doudet D (2011) Inverse association between dopaminergic neurotransmission and Iowa Gambling Task performance in pathological gamblers and healthy controls. Scand J Psychol 52:28-34.

Logan J, Fowler JS, Volkow ND, Wang GJ, Ding YS, Alexoff DL (1996) Distribution volume ratios without blood sampling from graphical analysis of PET data. J Cereb Blood Flow Metab 16:834-840.

Machado RB, Hipólide DC, Benedito-Silva AA, Tufik S (2004) Sleep deprivation induced by the modified multiple platform technique: quantification of sleep loss and recovery. Brain Res 1004:45-51.

McKenna BS, Dickinson DL, Orff HJ, Drummond SP (2007) The effects of one night of sleep deprivation on known-risk and ambiguous-risk decisions. J Sleep Res 16:245-252.

Nishino S, Mao J, Sampathkumaran R, Shelton J (1998) Increased dopaminergic transmission mediates the wake-promoting effects of CNS stimulants. Sleep Res Online 1:49-61.

Ongini E, Bonizzoni E, Ferri N, Milani S, Trampus M (1993) Differential effects of dopamine D-1 and D-2 receptor antagonist antipsychotics on sleep-wake patterns in the rat. J Pharmacol Exp Ther 266:726-731.

Porkka-Heiskanen T, Strecker RE, Thakkar M, Bjorkum AA, Greene RW, McCarley RW (1997) Adenosine: a mediator of the sleep-inducing effects of prolonged wakefulness. Science 276:1265-1268.

Qu WM, Huang ZL, Xu XH, Matsumoto N, Urade Y (2008) Dopaminergic D1 and D2 receptors are essential for the arousal effect of modafinil. J Neurosci 28:8462-8469.

Qu WM, Xu XH, Yan MM, Wang YQ, Urade Y, Huang ZL (2010) Essential role of dopamine $\mathrm{D} 2$ receptor in the maintenance of wakefulness, but not in homeostatic regulation of sleep, in mice. J Neurosci 30:4382-4389.

Schiffer WK, Azmoodeh M, Gerasimov M, Volkow ND, Fowler JS, Dewey SL (2003) Selegiline potentiates cocaine-induced increases in rodent nucleus accumbens dopamine. Synapse 48:35-38.

Schwierin B, Borbély AA, Tobler I (1996) Effects of N6-cyclopentyladenosine and caffeine on sleep regulation in the rat. Eur J Pharmacol 300:163-171.

Shang Y, Haynes P, Pírez N, Harrington KI, Guo F, Pollack J, Hong P, Griffith LC, Rosbash M (2011) Imaging analysis of clock neurons reveals light buffers the wake-promoting effect of dopamine. Nat Neurosci 14:889-895.

Skinbjerg M, Ariano MA, Thorsell A, Heilig M, Halldin C, Innis RB, Sibley DR (2009) Arrestin 3 mediates D(2) dopamine receptor internalization. Synapse 63:621-624.
Skinbjerg M, Liow JS, Seneca N, Hong J, Lu S, Thorsell A, Heilig M, Pike VW, Halldin C, Sibley DR, Innis RB (2010) D2 dopamine receptor internalization prolongs the decrease of radioligand binding after amphetamine: a PET study in a receptor internalization-deficient mouse model. Neuroimage 50:1402-1407.

Solt K, Cotten JF, Cimenser A, Wong KF, Chemali JJ, Brown EN (2011) Methylphenidate actively induces emergence from general anesthesia. Anesthesiology 115:791-803.

Sun W, Ginovart N, Ko F, Seeman P, Kapur S (2003) In vivo evidence for dopamine-mediated internalization of D2-receptors after amphetamine: differential findings with $[3 \mathrm{H}]$ raclopride versus $[3 \mathrm{H}]$ spiperone. Mol Pharmacol 63:456-462.

Thakkar MM, Winston S, McCarley RW (2003) Al receptor and adenosinergic homeostatic regulation of sleep-wakefulness: effects of antisense to the $\mathrm{Al}$ receptor in the cholinergic basal forebrain. J Neurosci 23:4278-4287.

Thanos PK, Bermeo C, Wang GJ, Volkow ND (2011) D-cycloserine facilitates extinction of cocaine self-administration in rats. Synapse 65:938-944.

Tomasi D, Wang RL, Telang F, Boronikolas V, Jayne MC, Wang GJ, Fowler JS, Volkow ND (2009) Impairment of attentional networks after 1 night of sleep deprivation. Cereb Cortex 19:233-240.

Volkow ND, Wang GJ, Fowler JS, Logan J, Schlyer D, Hitzemann R, Lieberman J, Angrist B, Pappas N, MacGregor R (1994) Imaging endogenous dopamine competition with [11C] raclopride in the human brain. Synapse 16:255-262.

Volkow ND, Ding YS, Fowler JS, Wang GJ, Logan J, Gatley SJ, Schlyer DJ, Pappas N (1995) A new PET ligand for the dopamine transporter: studies in the human brain. J Nucl Med 36:2162-2168.

Volkow ND, Wang GJ, Fowler JS, Gatley SJ, Logan J, Ding YS, Hitzemann R, Pappas N (1998) Dopamine transporter occupancies in the human brain induced by therapeutic doses of oral methylphenidate. Am J Psychiatry 155:1325-1331.

Volkow ND, Wang G, Fowler JS, Logan J, Gerasimov M, Maynard L, Ding Y, Gatley SJ, Gifford A, Franceschi D (2001) Therapeutic doses of oral methylphenidate significantly increase extracellular dopamine in the human brain. J Neurosci 21:RC121.

Volkow ND, Wang GJ, Fowler JS, Logan J, Franceschi D, Maynard L, Ding YS, Gatley SJ, Gifford A, Zhu W, Swanson JM (2002a) Relationship between blockade of dopamine transporters by oral methylphenidate and the increases in extracellular dopamine: therapeutic implications. Synapse 43:181-187.

Volkow ND, Wang GJ, Fowler JS, Logan J, Jayne M, Franceschi D, Wong C, Gatley SJ, Gifford AN, Ding YS, Pappas N (2002b) "Nonhedonic" food motivation in humans involves dopamine in the dorsal striatum and methylphenidate amplifies this effect. Synapse 44:175-180.

Volkow ND, Wang GJ, Fowler JS, Ding YS (2005) Imaging the effects of methylphenidate on brain dopamine: new model on its therapeutic actions for attention-deficit/hyperactivity disorder. Biol Psychiatry 57:1410-1415.

Volkow ND, Wang GJ, Telang F, Fowler JS, Logan J, Wong C, Ma J, Pradhan K, Tomasi D, Thanos PK, Ferré S, Jayne M (2008) Sleep deprivation decreases binding of $[11 \mathrm{C}]$ raclopride to dopamine $\mathrm{D} 2 / \mathrm{D} 3$ receptors in the human brain. J Neurosci 28:8454-8461.

Volkow ND, Tomasi D, Wang GJ, Telang F, Fowler JS, Wang RL, Logan J, Wong C, Jayne M, Swanson JM (2009) Hyperstimulation of striatal D2 receptors with sleep deprivation: Implications for cognitive impairment. Neuroimage 45:1232-1240

Volkow ND, Wang GJ, Tomasi D, Kollins SH, Wigal TL, Newcorn JH, Telang FW, Fowler JS, Logan J, Wong CT, Swanson JM (2012) Methylphenidateelicited dopamine increases in ventral striatum are associated with long-term symptom improvement in adults with ADHD. J Neurosci 32:841-849.

von Zastrow M (2003) Mechanisms regulating membrane trafficking of G protein-coupled receptors in the endocytic pathway. Life Sci 74:217-224.

Wang GJ, Volkow ND, Fowler JS, Logan J, Pappas NR, Wong CT, Hitzemann RJ, Netusil N (1999) Reproducibility of repeated measures of endogenous dopamine competition with $[11 \mathrm{C}]$ raclopride in the human brain in response to methylphenidate. J Nucl Med 40:1285-1291.

Wisor JP, Nishino S, Sora I, Uhl GH, Mignot E, Edgar DM (2001) Dopaminergic role in stimulant-induced wakefulness. J Neurosci 21:1787-1794.

Yoder KK, Kareken DA, Morris ED (2008) What were they thinking? Cognitive states may influence $[11 \mathrm{C}]$ raclopride binding potential in the striatum. Neurosci Lett 430:38-42. 